Submission ID: 43948

\title{
Risk and Performance Analysis for Seismic Vibrators in the Far North
} Working Conditions

V. Smirnov* (PJSC Novatek), E. Bondarev ("Arctic SPG 1" LLC)

\section{SUMMARY}

The article gives the results of qualitative and quantitative assessment of risks arising from the use of seismic vibrator in the Far North conditions. The implemented stochastic Monte-Carlo modeling revealed that risk realization will result in average 20 per cent decrease in the estimated performance. Taking into account the influence of the risks, the potential performance was estimated for three major seismic vibration methods, which are single group of sources, flip-flop and slip-sweep. 
Анализ рисков и производительности при работе вибрационным источником в условиях Крайнего Севера

\section{В.Н. Смирнов* (ПАО «НОВАТЭК»), Е.Б. Бондарев (ООО «Арктик СПГ 1»)}

\section{Введение}

Приводятся результаты качественной и количественной оценки рисков, возникающих при использовании вибрационного источника в условиях Крайнего Севера. Выполненное стохастическое моделирование по методу Монте-Карло показало, что реализация рисков приведет к снижению расчетной производительности в среднем на $20 \%$. С учетом влияния рисков оценивается потенциальная производительность трех основных методов вибрационной сейсморазведки: одной группы источников, флип-флоп и слип-свип.

\section{Оценка потенциальной производительности вибрационного источника}

Рассмотрим следующие методики производства работ:

1. Общепринятая (одна группа вибраторов): последовательная отработка каждого ф.н. В этом случае у нас присутствуют затраты времени как на возбуждение колебаний, так и на прием и переезд вибраторов на следующую точку;

2. Флип-флоп (FF, flip-flop, последовательная регистрация несколькими группами вибраторов): при этом в то время как одна группа вибраторов проводит возбуждение (Тв), другая группа вибраторов перемещается на следующую точку, и, таким образом, время на переезд вибраторов (t) сокращается вплоть до 0;

3. Слип-свип (SS, slip-sweep, одновременная регистрация несколькими группами вибраторов): следующая группа вибраторов начинает возбуждение в момент, когда предыдущая группа вибраторов еще продолжает возбуждение. С учетом наличия особого временного цикла - slip time, характеризующего временную задержку между началом возбуждения групп вибраторов (причем эта задержка должна быть больше времени прослушивания [1]), можно сделать вывод, что данная методика наиболее применима для одиночных возбуждений.

Для расчетов производительности использовались следующие параметры: два свипа короткий (12сек) и длительный (60 сек), предварительное уплотняющее воздействие (12сек), количество накоплений варьировалось (4 для короткого свипа и 1 - для длинного), время прослушивания - 8сек, время переезда - 80сек, slip-time для слип-свип - 10сек, продолжительность работ - 8 часов в сутки. В итоге получены разные оценки производительности для разных свипов и методик производства работ (Рис. 1).

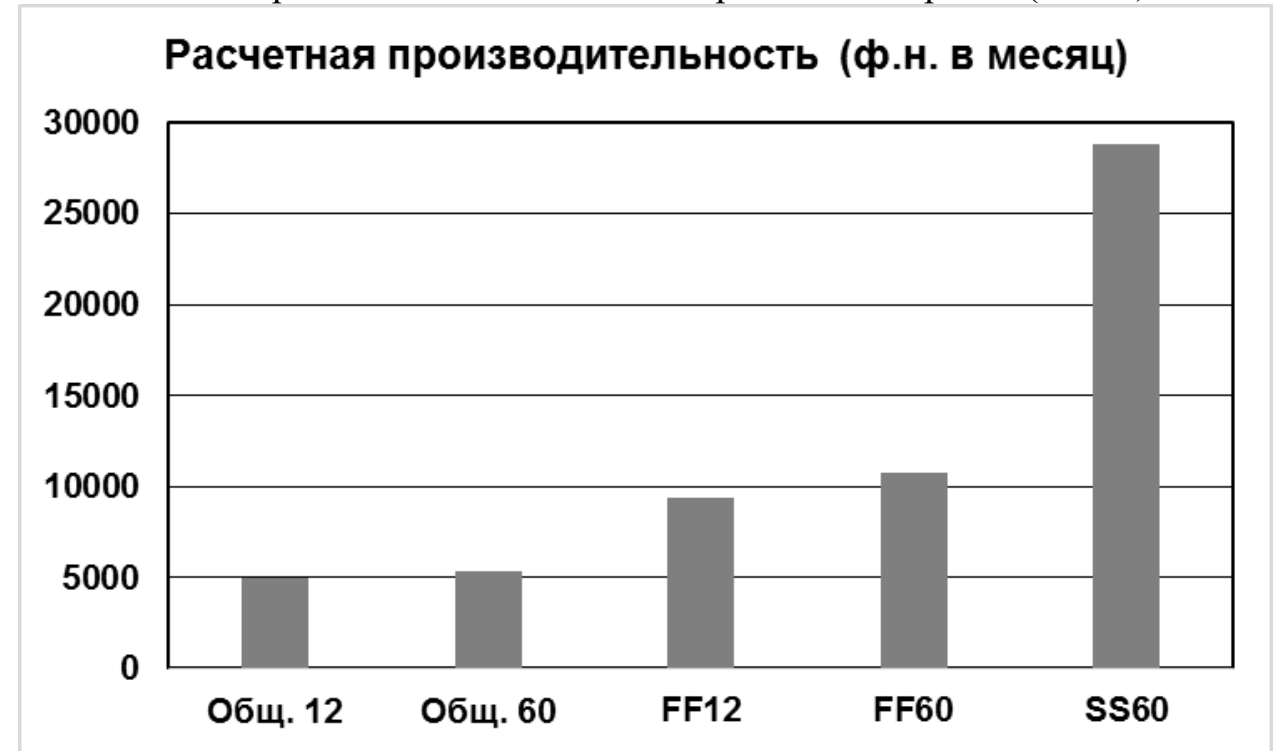

Рис. 1. Оценка производительности использования различных свипов и вариантов производства работ. 
Производительность может быть увеличена на 10-15\% (в случае слип-свип в 1.5 раза) при отказе от предварительного уплотняющего воздействия.

Данные расчеты применимы для сопоставления методик между собой, но в чистом виде не отражают реально достижимую производительность, которая будет ниже представленной из-за влияния реализующихся рисков. В расчетах учитывалось только время на отработку ф.н. и не учтены такие необходимые работы, как подготовка профилей и др.

\section{Оценка рисков при проведении полевых работ с вибрационными источниками}

Оценка рисков (особенно количественная) не является стандартной процедурой в области сейсморазведочных работ, хотя существуют положительные примеры подобных работ для проектов по обработке сейсмических данных [2]. Между тем, оценка рисков позволяет более точно оценить время, необходимое для выполнения проектного объема работ или, с другой стороны, оценить тот объем, которые реально успеть выполнить в ходе полевого сезона.

Реестр рисков (см. Таблицу 1) содержит основные (и притом негативные) риски, основными параметрами которых являются вероятность наступления и степень влияния. Эти параметры для каждого из рисков определены экспертно и могут меняться в зависимости от района, состояния вибраторов, ответственности Подрядчика и т.д.

Таблица 1. Реестр рисков

\begin{tabular}{|c|c|c|c|c|c|c|}
\hline № & Название & $\begin{array}{c}\text { Влияние, } \\
\text { месяц }\end{array}$ & $\begin{array}{l}\text { Вероятность } \\
\text { наступления }\end{array}$ & $\begin{array}{c}\text { Влияние на } \\
\text { длительность } \\
\text { этапа } \\
\end{array}$ & $\begin{array}{l}\text { Степень } \\
\text { влияния }\end{array}$ & $\begin{array}{l}\text { Итоговая } \\
\text { величина }\end{array}$ \\
\hline 1.1 & \multirow{6}{*}{$\begin{array}{c}\text { Выход из строя } \\
\text { вибраторов }\end{array}$} & $\begin{array}{c}0,5 \\
\text { декабря }\end{array}$ & 0,8 & $\begin{array}{c}\text { Увеличение на } \\
20 \%\end{array}$ & 0,4 & 0,32 \\
\hline 1.2 & & Январь & 0,1 & на $4 \%$ & 0,1 & 0,01 \\
\hline 1.3 & & Февраль & 0,3 & на 4\% & 0,1 & 0,03 \\
\hline 1.4 & & Март & 0,5 & на 4\% & 0,1 & 0,05 \\
\hline 1.5 & & Апрель & 0,7 & на $10 \%$ & 0,2 & 0,14 \\
\hline 1.6 & & май & 0,8 & на $20 \%$ & 0,4 & 0,32 \\
\hline 2 & $\begin{array}{c}\text { Невозможность } \\
\text { проезда }\end{array}$ & любой & 0,2 & на $50 \%$ & 1 & 0,2 \\
\hline 3 & $\begin{array}{l}\text { Неблагоприятные } \\
\text { погодные условия }\end{array}$ & любой & 0,3 & на $20 \%$ & 0,4 & 0,12 \\
\hline 4 & $\begin{array}{c}\text { Перебои в } \\
\text { обеспечении } \\
\text { ресурсами (топливо, } \\
\text { водители и т.п.) }\end{array}$ & любой & 0,1 & на $40 \%$ & 0,8 & 0,08 \\
\hline 5.1 & \multirow{3}{*}{ Риск утопления } & $\begin{array}{c}0,5 \\
\text { декабря } \\
\end{array}$ & 0,2 & на $10 \%$ & 0,2 & 0,04 \\
\hline 5.2 & & $\begin{array}{c}\text { Январь- } \\
\text { Апрель } \\
\end{array}$ & 0,1 & на $10 \%$ & 0,2 & 0,02 \\
\hline 5.3 & & Май & 0,2 & на $10 \%$ & 0,2 & 0,04 \\
\hline 6 & $\begin{array}{c}\text { Брак при отработке } \\
\text { ф.н. }\end{array}$ & любой & 0,2 & На 5\% & 0,1 & 0,02 \\
\hline
\end{tabular}

Соответствующая выделенным рискам матрица вероятности и степени влияния приводится на рисунке 2. Понятно, что наибольшее внимание необходимо уделять рискам с высокой вероятностью влияния и средней степенью влияния (1.1 и 1.6 - выход из строя вибратора в начале и в конце сезона) и с очень большой степенью влияния, хоть и при низкой вероятности наступления (2 - невозможность проезда и 4 - перебои в обеспечении ресурсами). Именно для этих рисков стоит разрабатывать план реагирования до начала полевого сезона и производства работ. 


\begin{tabular}{|c|c|c|c|c|c|c|c|c|c|}
\hline \multirow{2}{*}{$\begin{array}{l}\text { Вероят- } \\
\text { ность }\end{array}$} & \multicolumn{9}{|c|}{ Степень влияния } \\
\hline & 0,1 & 0,2 & 0,3 & 0,4 & 0,5 & 0,6 & 0,7 & 0,8 & 0,9 \\
\hline 0,9 & 0,09 & 0,18 & 0,27 & 0,36 & 0,45 & 0,54 & 0,63 & 0,72 & 0,81 \\
\hline 0,8 & 0,08 & 0,16 & 0,24 & $0,32(1.1)$ & 6,40 & 0,48 & 0,56 & 0,64 & 0,72 \\
\hline 0,7 & 0,07 & $0,141.5$ & 0,21 & 0,28 & 0,35 & 0,42 & 0,49 & 0,56 & 0,63 \\
\hline 0,6 & 0,06 & 0,12 & 0,18 & 0,24 & 0,30 & 0,36 & 0,42 & 0,48 & 0,54 \\
\hline 0,5 & $0,051.4$ & 0,10 & 0,15 & 0,20 & 0,25 & 0,30 & 0,35 & 0,40 & 0,45 \\
\hline 0,4 & 0,04 & 0,08 & 0,12 & 0,16 & 0,20 & 0,24 & 0,28 & 0,32 & 0,36 \\
\hline 0,3 & 0,03 & 0 & 0,09 & 0,123 & 0,15 & 0,18 & 0,21 & 0,24 & 0,27 \\
\hline 0,2 & 0,02 &, & 3),06 & 0,08 & 0,10 & 0,12 & 0,14 & 0,16 & 0,18 \\
\hline 0,1 & 0,01 1.2 & $0,02(5.2$ & 0,03 & 0,04 & 0,05 & 0,06 & 0,07 & $0,0 8 \longdiv { 4 }$ & 0,09 \\
\hline
\end{tabular}

Рис. 2. Матрица вероятности и степени влияния рисков при проведении работ с вибрационными источниками.

С учетом определенных характеристик рисков и исходя из планируемой производительности возможно выполнить имитационное моделирование по методу МонтеКарло и оценить реально достижимую производительность в ходе сезона. Результат моделирования, полученный в результате 1000 итераций, рассчитанных в ПО Oracle Primavera Risk Analysis, показывает увеличение длительности выполнения проекта на 1 месяц (оценка P50), что соответствует падению общей производительности на $20 \%$.

\section{Сопоставление длительности и стоимости производства полевых работ}

Сопоставление стоимости выполнялось с привлечением оценок одного из ведущих подрядчиков РФ. За основу расчета принят проект 500кв.км., площадь работ которого находится в труднодоступном районе ЯНАО. При этом рассмотрены 8 вариантов отработки, и расчеты стоимости приводятся относительно варианта 1 (отработка взрывом), стоимость которого приравнена к 1.

Производительность и длительность работ оценены с учетом выполненной оценки рисков и их влияния на производительность (Таблица 2).

Переход на высокоплотные системы наблюдений снижает возможности по отработке больших объемов за один полевой сезон или требует выполнения работ большим количеством групп вибраторов и такими методиками, как флип-флоп или слип-свип.

Таблица 2. Варианты систем наблюдения для расчета стоимости

\begin{tabular}{|c|c|c|c|c|c|c|c|c|c|c|}
\hline \multirow{2}{*}{ № } & \multicolumn{4}{|c|}{ Расстояние, м. } & \multirow{2}{*}{$\begin{array}{c}\text { Кол- } \\
\text { во } \\
\text { ф.н. }\end{array}$} & \multirow{2}{*}{$\begin{array}{c}\text { Активных } \\
\text { каналов }\end{array}$} & \multirow{2}{*}{ Отработка } & \multirow{2}{*}{ Стоимость } & \multirow{2}{*}{$\begin{array}{c}\text { Произв- } \\
\text { ть в } \\
\text { месяц } \\
\end{array}$} & \multirow{2}{*}{$\begin{array}{l}\text { Месяцев на } \\
\text { выполнение }\end{array}$} \\
\hline & ПП & ПВ & ЛВ & ЛП & & & & & & \\
\hline 1 & \multirow{5}{*}{\multicolumn{2}{|c|}{50}} & \multirow[b]{2}{*}{400} & \multirow[b]{2}{*}{300} & 25000 & 2048 & Взрыв & 1 & 5000 & 5,0 \\
\hline 2 & & & & & 25000 & 2048 & $\begin{array}{c}\text { Одна } \\
\text { группа }\end{array}$ & 0,8 & 4300 & 5,8 \\
\hline 3 & & & \multirow{6}{*}{\multicolumn{2}{|c|}{200}} & 50000 & 4096 & $\begin{array}{c}\text { Одна } \\
\text { группа }\end{array}$ & 1,0 & 4300 & 11,6 \\
\hline 4 & & & & & 50000 & 4096 & $\begin{array}{l}\text { Флип-флоп } \\
\text { (2 группы) }\end{array}$ & 0,9 & 8800 & 5,7 \\
\hline 5 & & & & & 50000 & 4096 & $\begin{array}{l}\text { Слип-свип } \\
\text { (3 группы) } \\
\end{array}$ & 1,0 & 23000 & 2,2 \\
\hline 6 & \multirow{3}{*}{\multicolumn{2}{|c|}{25}} & & & 100000 & 4096 & $\begin{array}{c}\text { Одна } \\
\text { группа }\end{array}$ & 1,9 & 4300 & 23,3 \\
\hline 7 & & & & & 100000 & 4096 & $\begin{array}{l}\text { Флип-флоп } \\
\text { (2 группы) }\end{array}$ & 1,7 & 8800 & 11,4 \\
\hline 8 & & & & & 100000 & 4096 & $\begin{array}{l}\text { Слип-свип } \\
\text { (3 группы) }\end{array}$ & 1,6 & 23000 & 4,3 \\
\hline
\end{tabular}




\section{Выводы}

Использование вибрационных источников в условиях крайнего севера и наличия снежного покрова требует применения предварительного уплотняющего воздействия, что снижает общую производительность работ на 7-10\%, а реализация разнообразных рисков приводит к снижению производительности еще на $20 \%$.

Переход на высокоплотные системы наблюдений снижает возможности по отработке больших объемов за один полевой сезон или требует выполнения работ большим количеством групп вибраторов и такими методиками, как флип-флоп или слип-свип.

В случае, если за один полевой сезон требуется выполнить отработку большого количества ф.н., то практически не остается иного варианта, кроме как переходить на вибрационный источник. Применение методик слип-свип при уплотнении ЛВ/ЛП до 200 м и при неизменном шаге ПВ/ПП, равном 50 м, позволит отрабатывать за сезон до 1000 кв.км. При этом стоимость работ будет сопоставима со стоимостью обычной взрывной $3 \mathrm{D}$ сейсморазведки при сопоставимом с точки зрения решения геологических задач качестве конечных результатов (если состояние верхнего слоя ВЧР благоприятствует использованию поверхностных источников).

\section{Библиография}

1. Mougenot D., 2004, Высокопроизводительный ВиброСейс - Приборы и системы разведочной геофизики, № 03, с. 9-11.

2. Смирнов В. Н., Ляндрес Ю. А., Рамазанов Д. Н., 2014, Оценка рисков на примере проекта по обработке сейсмических данных - Проблемы экономики и управления нефтегазовым комплексом, № 3, с. 24-28.

\section{References}

1. Mougenot D., 2004, High-performance VibroSeys - Russian scientific and technical journal «Instruments and systems of exploration geophysics», No. 03, p. 9-11.

2. Smirnov V., Lyandres Y., Ramazanov D., Risks assessment by the example of the project of seismic data processing - Russian scientific and technical journal «Problems of economics and management of oil and gas complex», No. 03, p. 24-28. 